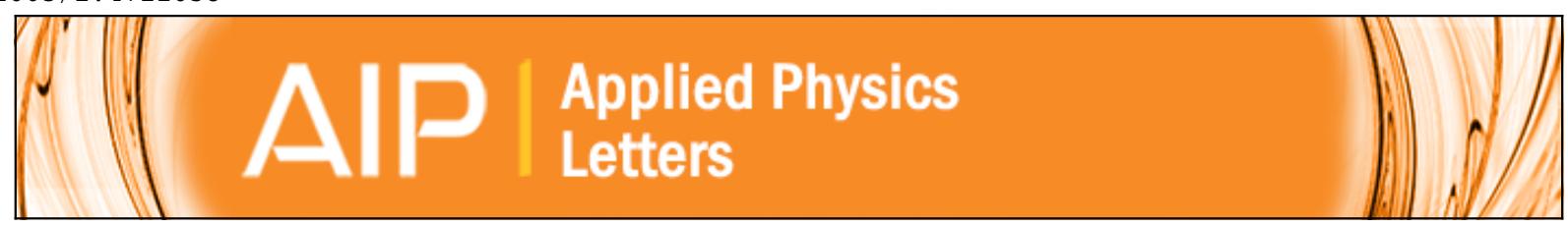

\title{
Defect and adsorbate induced ferromagnetic spin-order in magnesium oxide
} nanocrystallites

Ashok Kumar, Jitendra Kumar, and Shashank Priya

Citation: Applied Physics Letters 100, 192404 (2012); doi: 10.1063/1.4712058

View online: http://dx.doi.org/10.1063/1.4712058

View Table of Contents: http://scitation.aip.org/content/aip/journal/apl/100/19?ver=pdfcov

Published by the AIP Publishing

\section{AlP Re-register for Table of Content Alerts}




\title{
Defect and adsorbate induced ferromagnetic spin-order in magnesium oxide nanocrystallites
}

\author{
Ashok Kumar, ${ }^{1, a)}$ Jitendra Kumar, ${ }^{2}$ and Shashank Priya ${ }^{1, a)}$ \\ ${ }^{1}$ Center for Energy Harvesting Materials and Systems (CEHMS), Bio-inspired Materials and Devices \\ Laboratory (BMDL), Virginia Tech, Blacksburg, Virginia 24061, USA \\ ${ }^{2}$ Materials Science Programme, Indian Institute of Technology Kanpur, Kanpur 28016, India
}

(Received 13 February 2012; accepted 10 April 2012; published online 8 May 2012)

\begin{abstract}
We report the correlation between $d_{0}$ ferromagnetism, photoluminescence (PL), and adsorbed hydrogen $\left(\mathrm{H}^{-}\right)$species in magnesium oxide $(\mathrm{MgO})$ nanocrystallites. Our study suggests that the oxygen vacancies, namely singly ionized anionic vacancies $\left(\mathrm{F}^{+}\right)$and dimers $\left(\mathrm{F}_{2}{ }^{2+}\right)$ induce characteristic photoluminescence and the room-temperature ferromagnetic spin-order. Nanocrystallites with low population of oxygen vacancies have revealed diamagnetic behavior. Intriguingly, on adsorption of hydrogen $\left(\mathrm{H}^{-}\right)$species in the $\mathrm{MgO}$ nanocrystallites, ferromagnetic behavior was either enhanced (in the case of highly oxygen deficient nanocrystallites) or begun to percolate (in the case of nanocrystallite with low population density of oxygen vacancies). (C) 2012 American Institute of Physics. [http://dx.doi.org/10.1063/1.4712058]
\end{abstract}

The traditional understanding about the carrier induced origin of magnetic coupling has been recently challenged by two experimental facts. First, the oxide diluted magnetic semiconductors have revealed magnetism on both sides of metal insulator transition and second, defect-rich undoped oxides exhibited the room temperature ferromagnetism (RTFM). ${ }^{1,2}$ The origin of magnetic order in defect-rich undoped oxides is fundamentally and technologically fascinating as it does not results from partially filled $d$ orbitals. ${ }^{2}$ The phenomenon has been termed as $d_{0}$ magnetism. Venkatesan $\mathrm{et} \mathrm{al}^{3}$ have experimentally shown RTFM spin-order in pristine $\mathrm{HfO}_{2}$ thin films. The $a b$ initio electronic structure suggested that the origin of $\mathrm{FM}$ in $\mathrm{HfO}_{2}$ is due to cationic defects. ${ }^{4}$ Nevertheless, the cationic vacancies induced RTFM order in $\mathrm{HfO}_{2}$ was later questioned as the diamagnetic $\mathrm{HfO}_{2}$ powder exhibited weak ferromagnetic order after annealing in vacuum at $750^{\circ} \mathrm{C}$ for $2 \mathrm{~h}$, which in turn suggested origin of FM to be related to oxygen vacancies. ${ }^{5}$ Hong et al. ${ }^{6}$ observed RTFM in $\mathrm{TiO}_{2}, \mathrm{HfO}_{2}$, and $\mathrm{In}_{2} \mathrm{O}_{3}$, and reported that the annealing of $\mathrm{HfO}_{2}$ and $\mathrm{TiO}_{2}$ films in oxygen ambient degraded/destroyed ferromagnetic ordering. They suggested that both oxygen vacancies and confinement effects were key factors in inducing RTFM order. Sundaresan et al. ${ }^{7}$ recognized that the RTFM in $\mathrm{CeO}_{2}, \mathrm{Al}_{2} \mathrm{O}_{3}, \mathrm{ZnO}$, $\mathrm{In}_{2} \mathrm{O}_{3}$, and $\mathrm{SnO}_{2}$ nanograins originated from oxygen vacancies at the surface of nanograins.

Similar to $\mathrm{HfO}_{2}$, the $a b$ initio electronic structure calculation for rock-salt type crystals attributed the origin of $d_{0}$ magnetic moments and the resulting FM to spin polarized holes residing on cation $p$ orbitals either at vacancy or impurity sites. ${ }^{8}$ Moreover, unlike $\mathrm{HfO}_{2}$, the vacuum annealing of $\mathrm{MgO}$ films at $500^{\circ} \mathrm{C}$ exhibited reduced magnetic moments. ${ }^{9}$ It was assumed that vacuum annealing results in creation of oxygen vacancies, which subsequently reduces magnetic moments and, therefore, the observed RTFM spin-order was

\footnotetext{
a) Authors to whom correspondence should be addressed. Electronic addresses: spriya@vt.edu and ashokku@vt.edu. Tel.: +1 5402310745. Fax: +1 5402312903.
}

perceived as induced by magnesium vacancies. Recently, Maoz et al. ${ }^{10,11}$ noticed that air annealing too reduced magnetic spin-order in $\mathrm{MgO}$ nano-sheets and suggested one electron trapped oxygen vacancies $\left(\mathrm{F}^{+}\right)$to cause the observed ferromagnetic spin-order. Very recently, Wang et al. ${ }^{12}$ exhibited invariable magnetic moments when annealing in air was performed below $1000^{\circ} \mathrm{C}$. Further, Balcells et al. ${ }^{13}$ observed vacuum annealing of five months air exposed $\mathrm{MgO}$ thin films at $850^{\circ} \mathrm{C}$ to reveal enhanced magnetic moments.

It is important to note that nanocrystalline $\mathrm{MgO}$ is highly hygroscopic and forms diamagnetic $\mathrm{Mg}(\mathrm{OH})_{2}$ easily which, in turn, can reduce ferromagnetic spin-order. Moreover, hydrogen $\left(\mathrm{H}^{-}\right)$adsorption at oxygen vacancies and $\mathrm{Mg}^{2+}$ lattice sites may improve magnetic moments. These two processes are competitive and, in turn, will depend on factors such as grain size, defect concentration, nature of defects, and synthesis temperature. Hence, correlating the origin of ferromagnetic spin-order solely to annealing may be injudicious. While it is evident that defects induce the $d_{0}$ magnetic moments in $\mathrm{MgO}$ nanocrystallites, their nature is still not well understood. In this study, we will show that the oxygen vacancies can induce RTFM spin-order in $\mathrm{MgO}$ nanocrystallites, and hydrogen $\left(\mathrm{H}^{-}\right)$adsorption can drastically enhance the magnetic moments.

$\mathrm{MgO}$ nanocrystallites were synthesized through the solgel process. The magnesium nitrate hexahydrate $\left[\mathrm{Mg}\left(\mathrm{NO}_{3}\right)_{2}\right.$ $\left.6 \mathrm{H}_{2} \mathrm{O}\right]$ and oxalic acid $\left[(\mathrm{COOH})_{2} 2 \mathrm{H}_{2} \mathrm{O}\right]$ in $1: 1$ molar ratio were first dissolved separately in ethanol, and subsequently, mixed to yield a thick white gel $\left(\mathrm{MgC}_{2} \mathrm{O}_{4} 2 \mathrm{H}_{2} \mathrm{O}\right)$. The gel was digested for $12 \mathrm{~h}$ and dried afterward at $100^{\circ} \mathrm{C}$ for $24 \mathrm{~h}$, ground, sieved through 240 meshes, and calcined for $2 \mathrm{~h}$ each at $600^{\circ} \mathrm{C}$ (in air or oxygen) and $1000^{\circ} \mathrm{C}$ (in air) to yield $\mathrm{MgO}$. The samples were divided in two parts (a) as synthesized-studied within few hours after synthesis and (b) stored in desiccator for one month and studied afterward. The structures of as synthesized $\mathrm{MgO}$ nanocrystallites were investigated by $\mathrm{x}$-ray diffraction with $\mathrm{CuK}_{\alpha}$ radiation. The magnetic characterization of $\mathrm{MgO}$ samples was performed using a superconducting quantum interference device 
(SQUID) magnetometer (Quantum Design Inc.). A spectrofluorophotometer (Jovin-Yvon model Spex Fluorolog II) equipped with xenon lamp of $450 \mathrm{~W}$ as excitation source, suitable color filters, and a double monochromator was employed for obtaining the photoluminescence (PL) spectra. In addition, a FTIR spectrometer (BRUKER Vertex-70) was used for the detection of $\mathrm{Mg}-\mathrm{H}$ and $\mathrm{H}^{-}$type substitution mass defect induced infrared modes.

X-ray diffraction patterns of $\mathrm{MgO}$ nanocrystallites exhibited formation of periclase phase (results not shown due to brevity). Based on Scherrer's method, their average crystallite sizes $\left(\mathrm{t}_{\mathrm{av}}\right)$ were estimated as $6.0 \mathrm{~nm}$ (in oxygen at $600{ }^{\circ} \mathrm{C}$ for $2 \mathrm{~h}$ ), $9.5 \mathrm{~nm}$ (in air at $600{ }^{\circ} \mathrm{C}$ for $2 \mathrm{~h}$ ), and $73.5 \mathrm{~nm}$ (in air at $1000^{\circ} \mathrm{C}$ for $2 \mathrm{~h}$ ). The magnetization (M) versus magnetic field $(\mathrm{H})$ characteristic for these nanocrystallites observed at room temperature is shown in Figs. 1(a) and 1(b). The nanocrystallites $\left(t_{\mathrm{av}} \sim 9.5 \mathrm{~nm}\right)$ synthesized at $600{ }^{\circ} \mathrm{C}$ in air ambient exhibit RTFM with the magnitude of saturation magnetization, coercive field, and remanent magnetization as being $0.013 \mathrm{emu} / \mathrm{gm}, 98 \mathrm{Oe}$, and $4.2 \times 10^{-4}$ emu/gm, respectively. However, samples synthesized in oxygen atmosphere at $600{ }^{\circ} \mathrm{C}$ or at higher calcination temperature $\left(\sim 1000^{\circ} \mathrm{C}\right)$ in air ambient reveal diamagnetic behavior. Complete bleaching of RTFM in the samples synthesized in oxygen ambient suggests oxygen vacancy induced origin of $d_{o}$ magnetic moments. Moreover, above $900^{\circ} \mathrm{C}$ oxygen vacancies become mobile, which, in turn, can get annihilated easily at $1000^{\circ} \mathrm{C}$, and subsequently destroy RTFM spinorder. ${ }^{14}$ Very recently, Wang et al. ${ }^{12}$ noticed extinction of magnetic moments in air annealed $\mathrm{MgO}$ nanocrystals above $1000^{\circ} \mathrm{C}$, which may be due to bleaching of oxygen vacan-
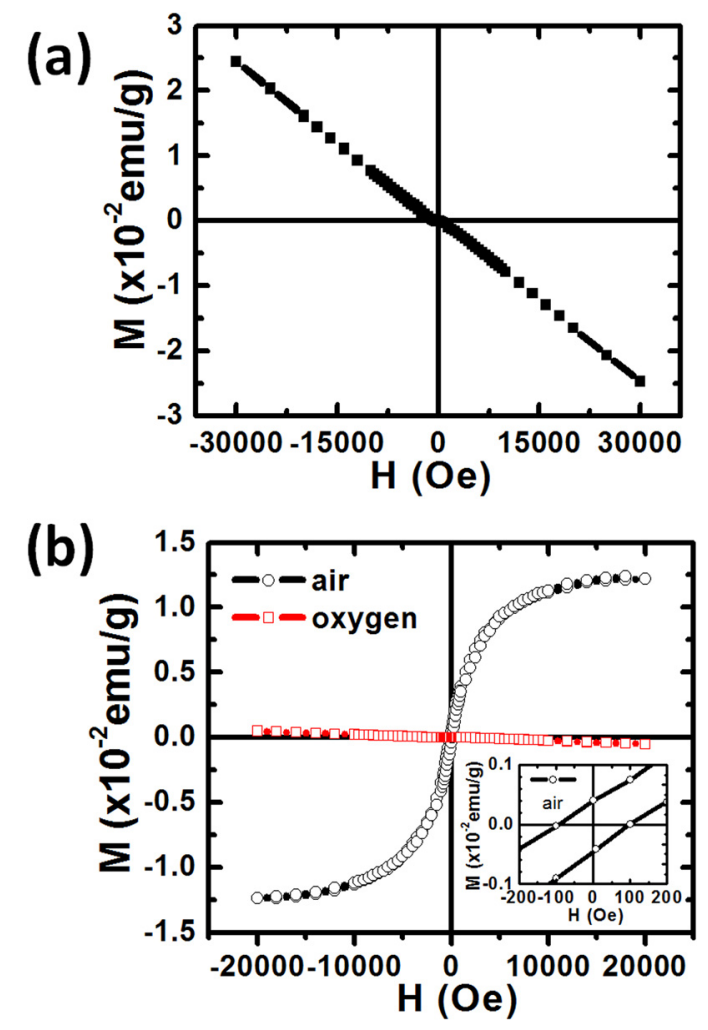

FIG. 1. Room temperature magnetization curve of $\mathrm{MgO}$ nanocrystallites synthesized at the calcination temperature of (a) $1000^{\circ} \mathrm{C}$ in air and (b) $600^{\circ} \mathrm{C}$ air and oxygen for $2 \mathrm{~h}$ each. cies. Our findings are consistent with the oxygen vacancies induced RTFM spin-order reported in oxides such as $\mathrm{HfO}_{2}$, $\mathrm{TiO}_{2}$, and $\mathrm{ZnO}$, etc. ${ }^{5,6}$

Fig. 2 shows PL emission spectra of $\mathrm{MgO}$ nanocrystallites for the samples calcined for $2 \mathrm{~h}$ each at $600{ }^{\circ} \mathrm{C}$ (in air or oxygen) and $1000^{\circ} \mathrm{C}$ (in air) recorded with excitation wavelengths of $350 \mathrm{~nm}$. The emission at wavelength $\sim 395 \mathrm{~nm}$ $\left(3.14 \mathrm{eV}\right.$ ) is due to ${ }^{2} \mathrm{~T}_{1 \mathrm{u}} \rightarrow{ }^{2} \mathrm{~A}_{1 \mathrm{~g}}$ transition of $\mathrm{F}^{+}$(an oxygen vacancy retaining one electron) center relaxation and can be compared with the $390 \mathrm{~nm}(3.18 \mathrm{eV})$ emission peak reported earlier by Rosenblatt et al. ${ }^{15} \mathrm{~A}$ broad emission band observed around $\sim 430 \mathrm{~nm}(2.88 \mathrm{eV})$ is arising due to ${ }^{3} \mathrm{~B}_{1 \mathrm{u}} \rightarrow{ }^{1} \mathrm{~A}_{\mathrm{g}}$ transitions of the $\mathrm{F}_{2}{ }^{2+}$ center in $\mathrm{D}_{2 \mathrm{~h}}$ symmetry. ${ }^{16}$ Such centers consist of two oxygen vacancies in nearest neighbor positions along $\langle 110\rangle$ with each having a trapped electron and have the ground and first excited states as ${ }^{1} \mathrm{~A}_{\mathrm{g}}$ and ${ }^{3} \mathrm{~B}_{1 \mathrm{u}}$, respectively. The presence of oxygen during decomposition favors reduction in anionic vacancies. As a consequence, defect density is considerably reduced in oxygen ambient vis-à-vis air. The formation of oxygen vacancies can be understood as below.

The stoichiometry of magnesium oxide obtained by thermal decomposition process of magnesium oxalate dihydrate is known to vary due to release of excess $\mathrm{CO}_{2}$ and less $\mathrm{CO}$ as given by the reaction ${ }^{17}$

$$
\begin{aligned}
\mathrm{MgC}_{2} \mathrm{O}_{4} \cdot 2 \mathrm{H}_{2} \mathrm{O} \rightarrow & \mathrm{MgO}_{1-\mathrm{x}}+(1+\mathrm{x}) \mathrm{CO}_{2}+(1-\mathrm{x}) \mathrm{CO} \\
& +2 \mathrm{H}_{2} \mathrm{O}
\end{aligned}
$$

with $\mathrm{x} \geq 0$ depending upon the temperature and atmosphere used. The decomposition process of magnesium oxalate dihydrate in oxygen allows conversion of $\mathrm{CO}$ to $\mathrm{CO}_{2}$. However, in air ambient (nitrogen $\sim 78 \%$ and oxygen $\sim 21 \%$ ), $\mathrm{CO}$ may escape as $\mathrm{CO}_{2}$ by consuming bulk/surface oxygen $\left(\mathrm{O}^{2-}\right)$ of $\mathrm{MgO}$ and forming $\mathrm{F}$ (an oxygen vacancy retaining two electrons) centers following the reaction:

$$
\mathrm{CO}+\mathrm{O}^{2-} \rightarrow \mathrm{CO}_{2}+\mathrm{F}
$$

Thus, the presence of nitrogen in air ambient helps in enhancing the population density of $\mathrm{F}^{-}$centers. However, at $1000{ }^{\circ} \mathrm{C}$, the emission intensity in air synthesized samples is even less than the samples synthesized in oxygen ambient at

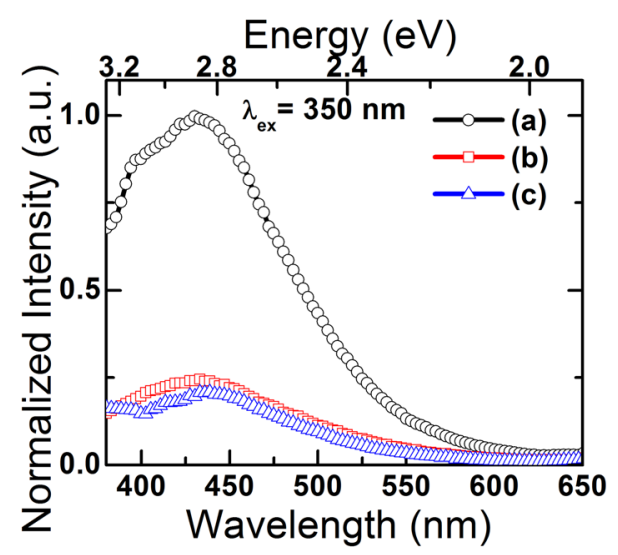

FIG. 2. The emission spectra of $\mathrm{MgO}$ nanocrystallites synthesized at the calcination temperature of (a) $600{ }^{\circ} \mathrm{C}$ in air, (b) $600{ }^{\circ} \mathrm{C}$ in oxygen, and (c) $1000^{\circ} \mathrm{C}$ in air for $2 \mathrm{~h}$ each with excitation wavelength of $350 \mathrm{~nm}$. 
$600{ }^{\circ} \mathrm{C}$ because above $900{ }^{\circ} \mathrm{C}$ oxygen vacancies become mobile and can get annihilated easily. ${ }^{14}$ Our result does not exclude the possibility of other types of defects like cation vacancies contributing to long range FM order; however, PL results together with observed FM confirm that oxygen vacancies play a crucial role in percolation of RTFM spinorder. Moreover, recently, it has been realized that even prohibitive cation defects $(\sim 4.6 \%$ more than the thermodynamically allowed), suggested as percolation threshold for FM spin-order would not lead to FM. ${ }^{10}$ The density functional theory (DFT) based calculations performed with local approximations of the exchange correlation potentials such as spin density approximation (LSDA) and the generalized gradient approximation (GGA) have themselves been criticized for their qualitative failures in description of hole centers in $\mathrm{MgO}^{18}$

Fig. 3(a) shows $\mathrm{M}-\mathrm{H}$ curves for $\mathrm{MgO}$ nanocrystallites stored in vacuum desiccator for one month and studied afterward. It is evident that saturation magnetization $\left(M_{s}\right)$ of the sample synthesized in air at $600{ }^{\circ} \mathrm{C}$ is doubled and saturation field is reduced by a factor of four. Another interesting observation is that the samples synthesized in oxygen ambient exhibited RTFM spin-order after storage; the values of $\mathrm{M}_{\mathrm{s}}$, coercive field $\left(\mathrm{H}_{\mathrm{c}}\right)$, and remanent magnetization $\left(\mathrm{M}_{\mathrm{rs}}\right)$ being, $0.0045 \mathrm{emu} / \mathrm{gm}, 48 \mathrm{Oe}$, and $9 \times 10^{-4} \mathrm{emu} / \mathrm{gm}$, respectively. The sample synthesized in air ambient exhibits the $M_{r s}$ value to be increased by the factor of six, while coercive field remains unchanged (98 Oe). Further, the sample synthesized in oxygen ambient reveals $\mathrm{M}_{\mathrm{s}}$ value as one third, $\mathrm{M}_{\mathrm{rs}}$ as twice,

(a)

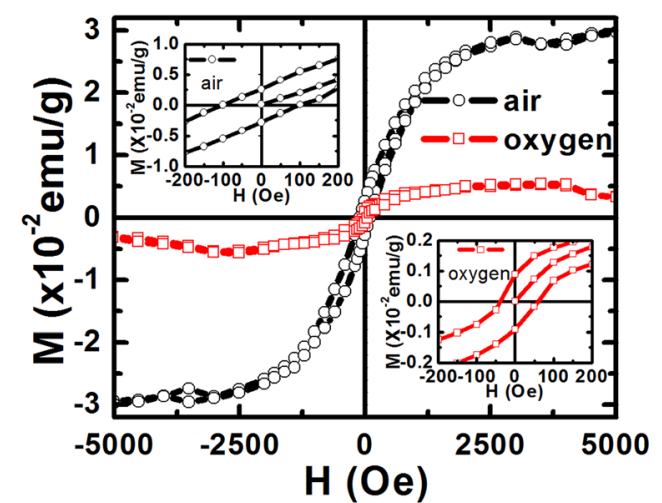

(b)

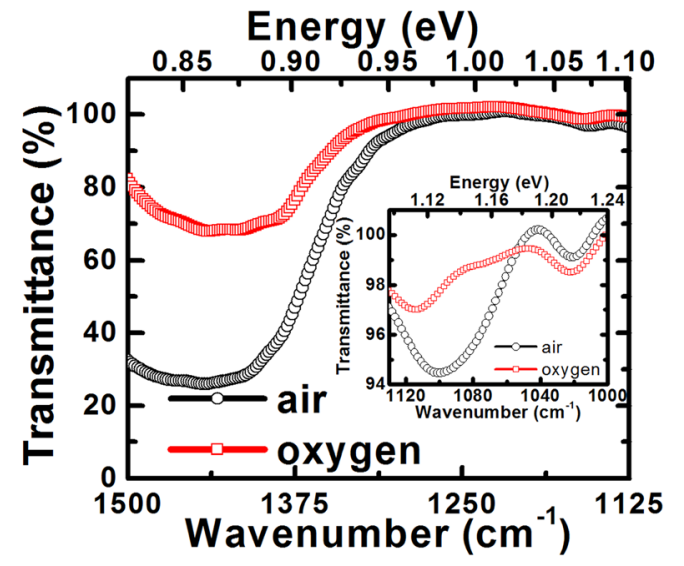

FIG. 3. Room temperature magnetization curve of $\mathrm{MgO}$ nanocrystallites (after storage in vacuum desiccator for one month) (a) and $\mathrm{Mg}-\mathrm{H}$ and $\mathrm{H}^{-}$ type substitution mass defect induced infrared modes in the wavenumber range $1500-1125$ and $1130-1000 \mathrm{~cm}^{-1}$ (b). and the coercive field value just half of the as-synthesized sample in air ambient. This indicates easy percolation of ferromagnetic spin-order after storage of samples. We believe that vacuum storage may result in trapping of various $\mathrm{H}^{-}$species at $\mathrm{Mg}^{2+}$ sites and substitution mass defect at F-type centers, which, in turn, can cause FM ordering due to an exchange interaction between the $\mathrm{H}^{-}$captured by oxygen vacancy and $\mathrm{Mg}^{2+}$ ions. This means that the spins of the localized defects (oxygen vacancy) will align with the nearby $\mathrm{Mg}^{2+}$ ions, producing an effective magnetic field and percolating the long range ferromagnetic interactions. Khalid et al. ${ }^{19}$ observed ferromagnetic spin-ordering due to hydrogenation in anionic vacancy rich $\mathrm{ZnO}$. Moreover, hydrogenation induced bleaching of magnetic moments has been reported in oxides showing cationic vacancies induced FM spin-order. ${ }^{13}$

Fig. 3(b) shows Fourier transform infrared (FTIR) spectra of $\mathrm{MgO}$ nanocrystallites stored in vacuum desiccator for one month. The absorption peaks observed around 14421462,1330 , and $1155-1162 \mathrm{~cm}^{-1}$ are attributed to the vibration of the $\mathrm{H}^{-}$species bonded to one, two, and three $\mathrm{Mg}^{2+}$ ions, respectively, which are similar to the bands observed at 1418-1430, 1325, and $1125 \mathrm{~cm}^{-1}$ in $\mathrm{MgO}$ crystallites treated with $\mathrm{H}_{2}{ }^{20-22}$ The source of hydrogen in $\mathrm{MgO}$ nanocrystallites is retained moisture which on heterolytic dissociation leads to surface hydride group and substitution mass defect $\mathrm{H}^{-}$at oxygen vacancies (inset of Fig. 3(b)) as

$$
\mathrm{Mg}_{\mathrm{LC}}^{2+}-\mathrm{F}+\mathrm{H}^{+}+\mathrm{H}^{-} \rightarrow \mathrm{Mg}_{\mathrm{LC}}^{2+}\left(\mathrm{H}^{-}\right)-\mathrm{F}\left(\mathrm{H}^{+}\right)
$$

The absorption bands noticed around 1020 and $1075 \mathrm{~cm}^{-1}$ are arising due to $\mathrm{H}^{-}$defect. This finding is similar to the observations of absorption bands at 1024, 1032, and $1053 \mathrm{~cm}^{-1}$ in $\mathrm{MgO}$ crystals grown by arc-fusion method and reduced subsequently. ${ }^{23}$ The shift (red or blue) of absorption bands is expected if $\mathrm{H}^{-}$defect occupies slightly different or distorted octahedral symmetry. The band at higher wavenumber $\sim 1100-1120 \mathrm{~cm}^{-1}$ is arising possibly due to $\mathrm{H}^{-}-\mathrm{H}^{-}$pairs on adjacent $\langle 110\rangle$ anion sites. Though it is obvious that $\mathrm{H}^{-}$ adsorption plays a vital role in percolation of FM spin-order, its mediating mechanism deserves further investigation.

In conclusion, our results revealed the existence of a close correlation between ferromagnetism, oxygen vacancies, namely singly ionized anionic vacancies $\left(\mathrm{F}^{+}\right)$and dimers $\left(\mathrm{F}_{2}{ }^{2+}\right)$, and adsorbed $\mathrm{H}^{-}$species. $\mathrm{MgO}$ nanocrystallites with poor population of oxygen defects exhibited diamagnetism, and subsequently RTFM on $\mathrm{H}^{-}$adsorption at $\mathrm{Mg}^{2+}$ sites, and substitution mass defect $\mathrm{H}^{-}$at oxygen vacancies. The undoped $\mathrm{MgO}$ nanocrystallites with tunable magnetic and optical properties may be promising to find applications in multifunctional photonic nanodevices.

This work was supported by the office of basic energy sciences, Department of energy through the Grant No. DEFG02-08ER 46484.

\footnotetext{
${ }^{1}$ T. Dietl, Nature Mater. 9, 965 (2010).

${ }^{2}$ L. Krusin-Elbaum, D. M. Newns, H. Zeng, V. Derycke, J. Z. Sun, and R. Sandstrom, Nature (London) 431, 672 (2004).

${ }^{3}$ M. Venkatesan, C. B. Fitzgerald, and J. M. D. Coey, Nature (London) 430, 630 (2004).

${ }^{4}$ C. D. Pemmaraju and S. Sanvito, Phys. Rev. Lett. 94, 217205 (2005).
} 
${ }^{5}$ J. M. D. Coey, M. Venkatesan, P. Stamenov, C. B. Fitzgerald, and L. S. Dorneles, Phys. Rev. B. 72, 024450 (2005).

${ }^{6}$ N. H. Hong, J. Sakai, N. Poirot, and V. Brizé, Phys. Rev. B 73, 132404 (2006).

${ }^{7}$ A. Sundaresan, R. Bhargavi, N. Rangarajan, U. Siddesh, and C. N. R. Rao, Phys. Rev. B 74, 161306 (2006).

${ }^{8}$ J. I. Beltrán, C. Monty, L. I. Balcells, and C. Martínez-Boubeta, Solid State Commun. 149, 1654 (2009).

${ }^{9}$ J. Hu, Z. Zhang, M. Zhao, H. Qin, and M. Jiang, Appl. Phys. Lett. 93, 192503 (2008).

${ }^{10}$ B. M. Maoz, E. Tirosh, M. B. Sadan, I. Popov, Y. Rosenberg, and G. Markovich, J. Mater. Chem. 21, 9532 (2011).

${ }^{11}$ B. M. Maoz, E. Tirosh, M. B. Sadan, and G. Markovich, Phys. Rev. B 83, 161201 (2011).

${ }^{12}$ D. D. Wang, Z. Q. Chen, C. Y. Li, X. F. Li, C. Y. Cao, and Z. Tang, "Correlation between ferromagnetism and defects in $\mathrm{MgO}$ nanocrystals studied by positron annihilation," Physica B (in press).
${ }^{13}$ L. I. Balcells, J. I. Beltrán, C. Martínez-Boubeta, Z. Konstantinović, J. Arbiol, and B. Martínez, Appl. Phys. Lett. 97, 252503 (2010).

${ }^{14}$ Y. Chen, R. T. Williams, and W. A. Sibley, Phys. Rev. 182, 960 (1969).

${ }^{15}$ G. H. Rosenblatt, M. W. Rowe, G. P. Williams, Jr., R. T. Williams, and Y. Chen, Phys. Rev. B 39, 10309 (1989).

${ }^{16}$ J. D. Bolton, B. Henderson, and D. O. O'Connell, Solid State Commun. 38, 287 (1981).

${ }^{17}$ P. E. Yankwich and P. D. Zavitsanos, J. Phys. Chem. 69, 442 (1965).

${ }^{18}$ A. Droghetti, C. D. Pemmaraju, and S. Sanvito, Phys. Rev. B 81, 092403 (2010).

${ }^{19}$ M. Khalid, P. Esquinazi, D. Spemann, W. Anwand, and G. Brauer, New J. Phys. 13, 063017 (2011).

${ }^{20}$ E. N. Gribov, S. Bertarione, D. Scarano, C. Lamberti, G. Spoto, and A. Zecchina, J. Phys. Chem. B 108, 16174 (2004).

${ }^{21}$ A. Kumar and J. Kumar, Solid State Commun. 147, 405 (2008).

${ }^{22}$ A. Kumar, S. Thota, S. Varma, and J. Kumar, J. Lumin. 131, 640 (2011).

${ }^{23}$ R. González, Y. Chen, and M. Mostoller, Phys. Rev. B 24, 6862 (1981). 